\title{
Commentary Is the way to man's heart (and lung) through the abdomen?
} Robert L Owens ${ }^{1}$, R Scott Harris ${ }^{2}$ and Atul Malhotra ${ }^{1}$

\author{
${ }^{1}$ Sleep Disorders Research Program, Division of Sleep Medicine, Brigham and Women's Hospital and Harvard Medical School, \\ 221 Longwood Avenue, Boston, MA 02115, USA \\ ${ }^{2}$ Department of Medicine, Pulmonary and Critical Care Unit, Bulfinch 148, Massachusetts General Hospital and Harvard Medical School, Boston, \\ MA 02114, USA
}

Corresponding author: Robert L Owens, rowens@partners.org

Published: 6 November 2009

Critical Care 2009, 13:199 (doi:10.1186/cc8136)

This article is online at http://ccforum.com/content/13/6/199

(c) 2009 BioMed Central Ltd

See related research by Krebs et al., http://ccforum.com/content/13/5/R160

\begin{abstract}
Intra-abdominal hypertension is increasingly recognized to be both prevalent and clinically important in medical and surgical intensive care units. Intra-abdominal pressure (IAP) can impact organ function throughout the body, and it can also complicate standard measurements used in intensive care units. The article by Krebs and colleagues reports the effect of IAP on respiratory function, gas exchange and hemodynamic function. Their results show a relatively small effect of modestly elevated IAP on these variables in their patient population. However, their work raises several questions for clinicians and researchers regarding the pathophysiology and management of IAP.
\end{abstract}

In the previous issue of Critical Care, Krebs and colleagues systematically studied the effects of intra-abdominal hypertension (IAH) on cardiopulmonary function [1]. Such studies are very much needed for a number of reasons. Traditionally, trauma surgeons witnessed improvements in urinary output following laparatomy; but medical intensivists were slower to appreciate the importance of intra-abdominal pressure (IAP). $\mathrm{IAH}$ is highly prevalent, however, in both surgical and medical intensive care units [2], although the causes may differ. $\mathrm{IAH}$ may become an even greater issue in the medical intensive care unit with the obesity pandemic, since body mass index is the best independent predictor of IAP [2].

Furthermore, several studies have shown that IAH has prognostic importance through effects on both intra-abdominal and intrathoracic organ function [3]. That is, increased IAP causes pleural pressure elevations that affect cardiopulmonary function [4]. Hepatic and renal compromise has been reported, presumably through compression of venules. We have previously observed patients with presumed hepatorenal syndrome (a diagnosis with ostensibly up to $100 \%$ mortality) who were markedly improved by lowering
IAP via paracentesis, suggesting $\mathrm{IAH}$ as a cause for their renal failure [5]. In addition, marked elevations in intracranial pressure have been observed with increasing IAP, presumably through reductions in venous return from the head [6]. Beyond these end organ effects, elevations in IAP can also impact measurement of respiratory and hemodynamic parameters [7]. For example, the central venous pressure - typically measured with reference to atmosphere can be elevated in patients with IAH. These elevated values of central venous pressure do not reflect excess preload, however, but instead reflect external compression of the right atrium (by elevated pleural pressure in the setting of IAH) that raises central venous pressure even with very little volume within the atrium. Based on the appreciation of the importance of IAP, there is now renewed interest in the measurement of intrathoracic pressure.

How to incorporate these pressure measurements into clinical practice raises several issues. First, the use of esophageal pressure to estimate pleural pressure has been questioned [8], since elevated values were presumed to be an artifact of cardiac weight. Sustained elevations in pleural pressure would imply negative transpulmonary pressure (classically defined as airway opening pressure minus pleural pressure [9]), which some individuals have argued cannot occur. These negative values (pleural pressure in excess of the airway opening pressure) are routinely seen during forced exhalation, however, and are commonly observed with the development of atelectasis, airway closure, alveolar flooding and/or expiratory flow limitation [10].

Second, the slope of a pressure-volume curve reflects the compliance (or elastance) of the respiratory system, regardless of the position of the curve [11]. That is, we have

$\mathrm{IAH}=$ intra-abdominal hypertension; $\mathrm{IAP}=$ intra-abdominal pressure. 
observed normal respiratory system compliance in obesity, despite markedly shifted curves (baseline pleural pressure elevations but a normal slope) $[10,12,13]$. Both the slope and the pressure intercept of the pressure-volume curve are therefore needed to define the mechanical behavior of the respiratory system.

Third, the transmission of IAP to the thorax may depend on the disease state and/or chronicity. As such, it is unknown whether acute elevations in IAP (as seen in trauma or surgical intensive care unit patients) would have the same impact on intrathoracic pressures as would chronic elevations (due to obesity or cirrhosis with ascites, for example), since diaphragm remodeling may occur over time [14]. Moreover, in nonparalyzed patients, ongoing diaphragmatic activity could attenuate pressure transmission from the abdomen to the thorax. Careful attention to these physiological issues is required when examining the clinical literature.

In their study, Krebs and colleagues report minimal effect of IAP on respiratory function, gas exchange, and hemodynamic function. The findings are very interesting and somewhat surprising. The lack of observed effect of IAP on pleural pressure may reflect the relatively modest elevations in IAP. In addition, given that these IAH patients were primarily surgical and were relatively lean (by US standards), the findings may have been different in more obese patients with more marked and sustained elevations in abdominal (and thus pleural) pressure. In addition, we are unclear as to whether ongoing diaphragmatic activity was present in this study - which may have increased the tension across the diaphragm and perhaps minimized the influence of IAP on pleural pressure.

These results raise some important issues. For the clinician, the take-home message from the present paper might be that the correlation between IAP and pleural pressure is poor within the range studied, necessitating direct measurement of intrathoracic pressure if this value is required. Further work will be necessary to determine the utility of these measurements in influencing patient outcome, particularly in patients with acute respiratory distress syndrome [15,16]. In the Krebs and colleagues study population, more marked IAP elevations may be required to have an important clinical impact. For the scientist, careful studies on diaphragm remodeling in the setting of obesity and critical illness would be of interest. In addition, regional variations in pleural pressure and their influences on local pulmonary mechanics should be assessed. Finally, although cardiac weight has only a minor effect on esophageal pressure measurements in normal subjects [17], further validation of these techniques in critically ill patients would be of interest.

\section{Competing interests}

The authors declare that they have no competing interests.

\section{References}

1. Krebs J, Pelosi P, Tsagogiorgas C, Alb M, Luecke T: Effects of positive end-expiratory pressure on respiratory function and hemodynamics in patients with acute respiratory failure with and without intra-abdominal hypertension: a pilot study. Crit Care 2009, 13:R160.

2. Malbrain ML, Chiumello D, Pelosi P, Wilmer A, Brienza N, Malcangi V, Bihari D, Innes R, Cohen J, Singer P, Japiassu A, Kurtop E, De Keulenaer BL, Daelemans R, Del Turco M, Cosimini P, Ranieri M, Jacquet L, Laterre PF, Gattinoni L: Prevalence of intraabdominal hypertension in critically ill patients: a multicentre epidemiological study. Intensive Care Med 2004, 30:822-829.

3. Malbrain ML, Chiumello D, Pelosi P, Bihari D, Innes R, Ranieri VM, Del Turco M, Wilmer A, Brienza N, Malcangi V, Cohen J, Japiassu A, De Keulenaer BL, Daelemans R, Jacquet L, Laterre PF, Frank $G$, de Souza P, Cesana B, Gattinoni L: Incidence and prognosis of intraabdominal hypertension in a mixed population of critically ill patients: a multiple-center epidemiological study. Crit Care Med 2005, 33:315-322.

4. Malhotra A, Hillman D: Obesity and the lung: 3. Obesity, respiration and intensive care. Thorax 2008, 63:925-931.

5. Jain D, Dorairajan S, Misra M: Ascites, a new cause for bilateral hydronephrosis: case report. ScientificWorldJournal 2009, 9: 1035-1039.

6. De laet I, Citerio G, Malbrain ML: The influence of intraabdominal hypertension on the central nervous system: current insights and clinical recommendations, is it all in the head? Acta Clin Belg Supp/ 2007, 1:89-97.

7. Gilroy RJ, Jr, Lavietes MH, Loring SH, Mangura BT, Mead J: Respiratory mechanical effects of abdominal distension. J Appl Physiol 1985, 58:1997-2003.

8. Hager DN, Brower RG: Customizing lung-protective mechanical ventilation strategies. Crit Care Med 2006, 34:1554-1555.

9. Mead J, Takishima T, Leith D: Stress distribution in lungs: a model of pulmonary elasticity. J Appl Physiol 1970, 28:596608.

10. Talmor D, Sarge T, O'Donnell CR, Ritz R, Malhotra A, Lisbon A, Loring SH: Esophageal and transpulmonary pressures in acute respiratory failure. Crit Care Med 2006, 34:1389-1394.

11. Harris RS, Hess DR, Venegas JG: An objective analysis of the pressure-volume curve in the acute respiratory distress syndrome. Am J Respir Crit Care Med 2000, 161:432-439.

12. Owens RL, Hess DR, Malhotra A, Venegas JG, Harris RS: Effect of the chest wall on pressure-volume curve analysis of acute respiratory distress syndrome lungs. Crit Care Med 2008, 36: 2980-2985.

13. Caramez MP, Kacmarek RM, Helmy M, Miyoshi E, Malhotra A, Amato MB, Harris RS: A comparison of methods to identify open-lung PEEP. Intensive Care Med 2009, 35:740-747.

14. Similowski T, Yan S, Gauthier AP, Macklem PT, Bellemare F: Contractile properties of the human diaphragm during chronic hyperinflation. $N$ Engl J Med 1991, 325:917-923.

15. Talmor D, Sarge T, Malhotra A, O'Donnell CR, Ritz R, Lisbon A, Novack V, Loring SH: Mechanical ventilation guided by esophageal pressure in acute lung injury. N Engl J Med 2008, 359:2095-2104.

16. Malhotra A: Low-tidal-volume ventilation in the acute respiratory distress syndrome. N Engl J Med 2007, 357:1113-1120.

17. Washko GR, O'Donnell CR, Loring SH: Volume-related and volume-independent effects of posture on esophageal and transpulmonary pressures in healthy subjects. J Appl Physiol 2006, 100:753-758. 